\title{
Pembuatan Roda Gigi dari Bahan Serbuk Logam Tembaga dan Alumunium dengan Proses Kompaksi
}

\author{
Abdul Syukur Alfauzi", Adhy Purnomo, Bambang Tjahjono, Hariyanto, Nur sa'adah \\ Program Studi Teknik Mesin, Jurusan Teknik Mesin, Politeknik Negeri Semarang \\ Jl.Prof.H.Sudarto,SH. Tembalang, Semarang \\ *E-mail: abdlsyukura@gmail.com
}

Diterima: 04-12-2019; Direvisi: 20-12-2019; Dipublikasi: 31-12-2019

\begin{abstract}
Abstrak
Roda gigi adalah bagian dari mesin yang berputar dan berguna untuk mentransmisikan daya. Pembuatan roda gigi pada umumnya dibuat dengan proses pemesinan. Tujuan penelitian ini membuat roda gigi dari bahan serbuk logam tembag, alumunium dan paduan keduanya dengan proses kompaksi. Kompaksi adalah proses penekanan terhadap serbuk logam agar dapat menyatu satu dengan lainnya sebelum ditingkatkan ikatannya dengan proses sintering. Proses ini dilakukan dengan menggunakan bahan baku dari serbuk tembaga, aluminium dan paduan keduanya sebagai bahan bakunya. Proses kompaksi menggunakan mesin cetak hidrolik yang berkemampuan tekan 6 ton, hasil cetak roda gigi yang dilakukan dari bahan serbuk tembaga, selanjutnya dilakukan proses sintering dengan temperatur $868{ }^{\circ} \mathrm{C}$ dan waktu penahanan 1 jam sebelum dilakukan uji kekerasan. Pengujian kekerasan dilakukan dengan metode Brinell dengan beban $6,25 \mathrm{~kg}$ dan diameter indentor sebesar 2,5 mm dengan menggunakan mesin uji kekerasan GNEHM HORGEN beserta perlengkapannya. Hasil pengujian kekerasan yang dilakukan terjadi pada roda gigi dari bahan serbuk tembaga $75 \%$ dan $25 \%$ aluminium.
\end{abstract}

Kata kunci: Metalurgi Serbuk; Mesin Cetak Hidrolik; Roda Gigi; Sintering

\begin{abstract}
A gear is a part of a rotating machine and is useful for transmitting power. The making of gears is generally made by machining processes. The purpose of this study is to make gears from copper metal powder, aluminum and both alloys by compacting process. Compaction is the process of suppressing metal powders so that they can blend before bonding with the sintering process. This process is carried out using raw materials from copper, aluminum powder and both alloys as raw materials. The compacting process uses a hydraulic press that has the ability to press 6 tons, the results of the gear print are made of copper powder, then the sintering process is carried out at a temperature of $868{ }^{\circ} \mathrm{C}$ and a holding time is 1 hour before the hardness test is carried out. The hardness test is carried out by the Brinell method with a load of $6.25(\mathrm{~kg})$ and an indenter diameter of $2.5(\mathrm{~mm})$ using the GNEHM HORGEN hardness testing machine and its equipment. The results of hardness testing carried out on gears made of $75 \%$ copper powder and $25 \%$ aluminum.
\end{abstract}

Keywords: Powder Metallurgy; Hydraulic Printing Machines; Gears; Sintering

\section{Pendahuluan}

Bab Roda gigi adalah bagian dari mesin yang berputar dan berguna untuk mentransmisikan daya. Roda gigi memiliki gigi-gigi yang saling bersinggungan. Dua atau lebih roda gigi yang bersinggungan dan bekerja bersama-sama disebut transmisi roda gigi, dan menghasilkan keuntungan mekanis melalui rasio jumlah gigi. Roda gigi mampu mengubah kecepatan putar, torsi, dan arah daya terhadap sumber daya. Pada umumnya, roda gigi dibuat dengan proses pemesinan. Tetapi, dalam proses pembuatan roda gigi dengan pemesinan memiliki beberapa kelemahan yaitu hanya bisa membuat roda gigi dengan ukuran yang besar, banyak bahan yang terbuang, proses pembuatan yang relatif lama. Untuk mengatasi kelemahan tersebut kami memodifikasi mesin cetak EDM (Electric discharge machine) menjadi alat cetak roda gigi dari bahan serbuk tembaga dan aluminium dengan tenaga hidrolik [1-3].

Kelebihan dari alat cetak roda gigi yaitu bisa membuat roda gigi dengan ukuran kecil, menghemat bahan dan efisiensi waktu. Powder Metallurgy (metalurgi serbuk) adalah suatu kegiatan yang meliputi pembuatan benda komersial, baik yang jadi atau masih setengah jadi (disebut kompak mentah), dari serbuk logam melalui penekanan $[4,5]$. 
Penekanan terhadap serbuk dilakukan agar serbuk dapat menempel satu dengan lainnya sebelum ditingkatkan ikatannya dengan proses sintering. Dengan menggunakan mesin cetak tekan bertenaga hidrolik dengan gaya penekanan sebesar $60(\mathrm{kN})$ penulis bermaksud membuat roda gigi dari serbuk tembaga, aluminium, yang nantinya dapat membantu proses pembuatan roda gigi planetary untuk motor starter di industri manufaktur [4,6].

Roda gigi adalah bagian dari mesin yang berputar dan berguna untuk mentransmisikan daya. Roda gigi memiliki gigi-gigi yang saling bersinggungan. Dua atau lebih roda gigi yang bersinggungan dan bekerja bersama-sama disebut transmisi roda gigi, dan menghasilkan keuntungan mekanis melalui rasio jumlah gigi. Roda gigi mampu mengubah kecepatan putar, torsi, dan arah daya terhadap sumber daya. Ketika dua roda gigi dengan jumlah gigi yang tidak sama dikombinasikan, keuntungan mekanis bisa didapatkan, baik itu kecepatan putar maupun torsi yang dihitung dengan persamaan sederhana.

Keuntungan menggunakan roda gigi adalah:

a. Mentransmisi rasio kecepatan yang tepat.

b. Dapat digunakan untuk memindahkan daya yang besar.

c. Mempunyai efisiensi tinggi (power lost per gear set sekitar 0,5\% tergantung faktor penyelesaian gigi dan pelumasan).

d. Layout yang kompak.

Kerugian dari menggunakan roda gigi adalah :

a. Manufaktur roda gigi membutuhkan peralatan dan perlengkapan khusus.

b. Kesalahan pada pemotongan gigi dapat menyebabkan getaran dan noise selama pengoperasian.

\section{Material dan metodologi}

\subsection{Flowchart penelitian}

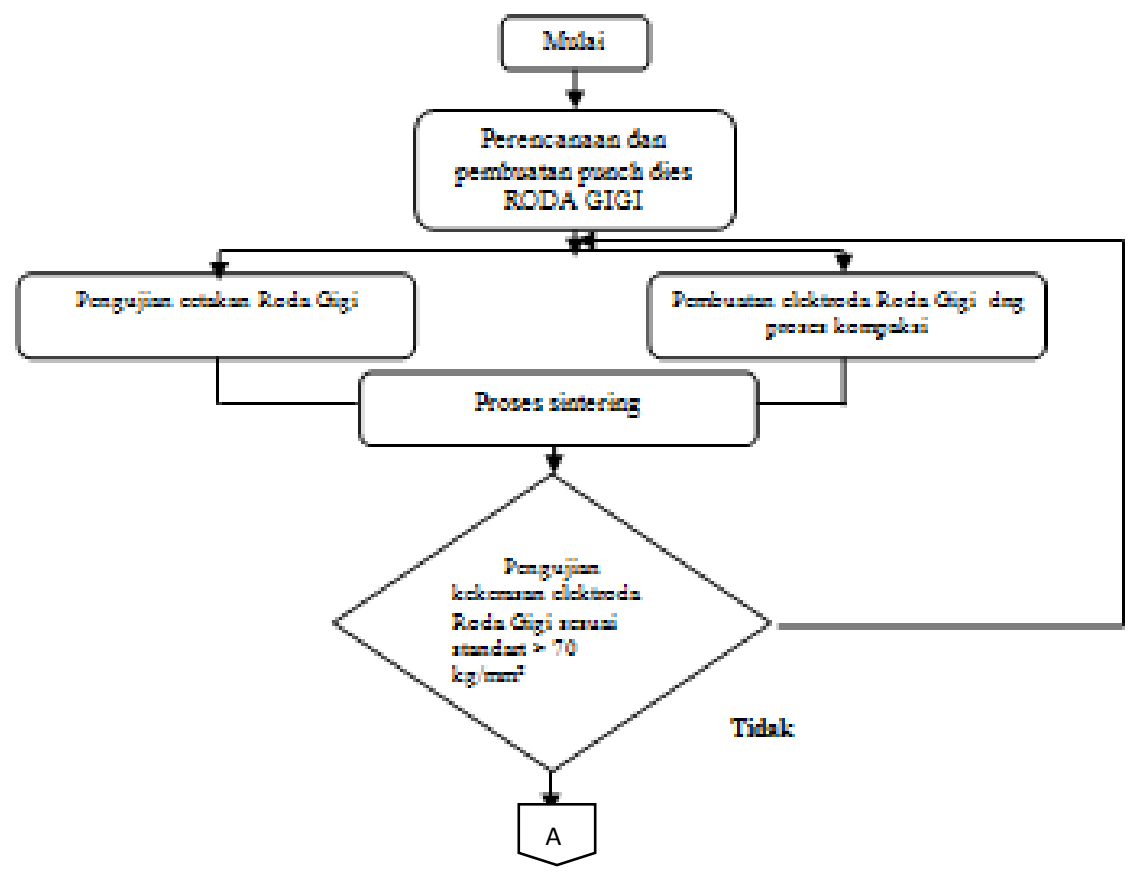

Gambar 1. Flowchart penelitian 


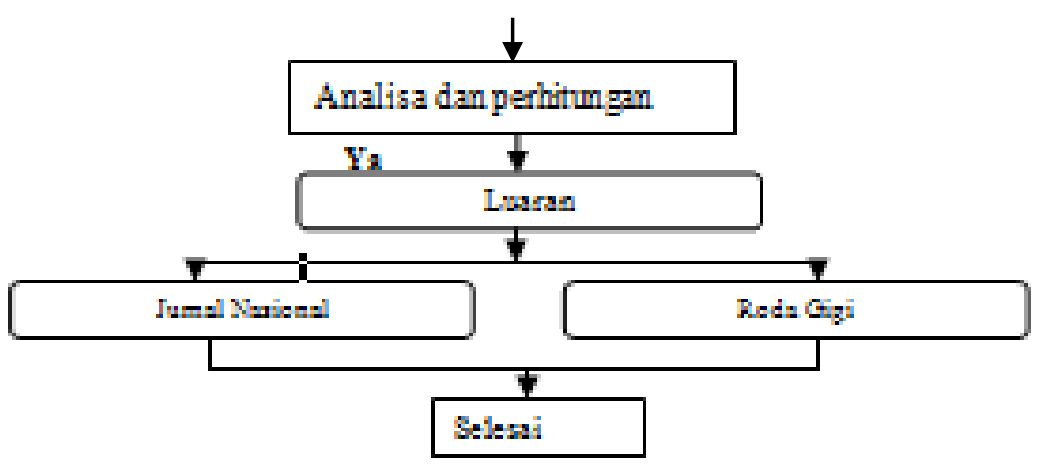

Gambar 1. Flowchart penelitian (lanjutan)

\subsection{Alat dan Bahan Penelitian}

Alat dan bahan yang digunakan dalam penelitian terlihat pada Gambar 2 dan 3. Gambar 2 merupakan bahan penelitian yang digunakan yaitu berupa berupa serbuk tembaga dan aluminium. Gambar 3 merupakan alat yang digunakan dalam penelitian berupa dapur listrik dan alat uji kekerasan.

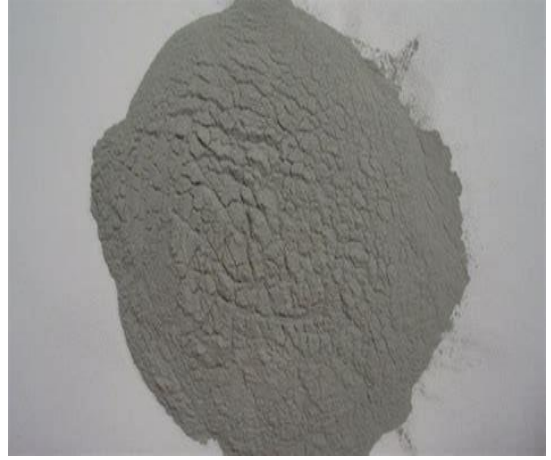

(a)

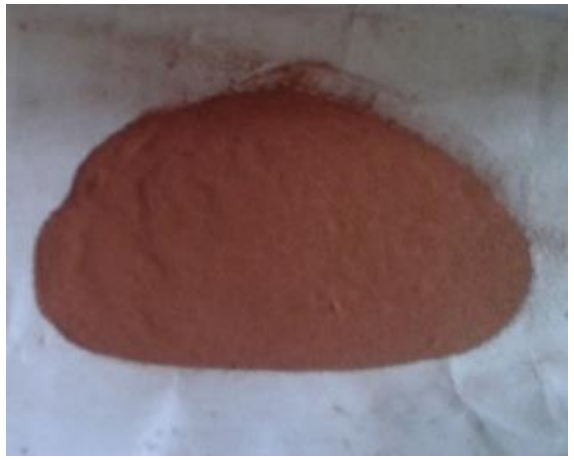

(b)

Gambar 2. Bahan penelitian (a) serbuk alumunium dan (b) serbuk tembaga

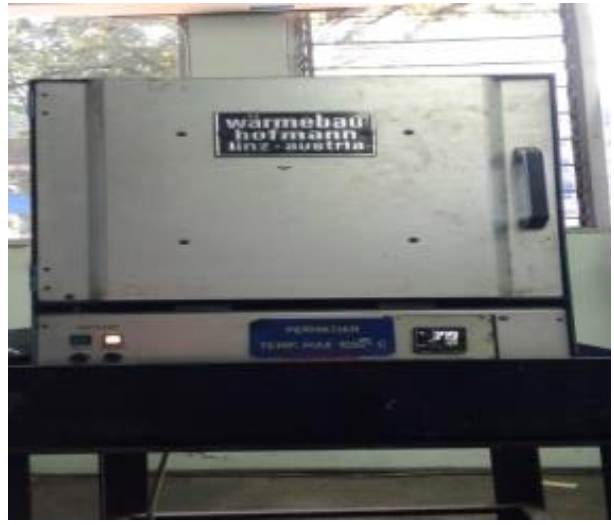

(a)

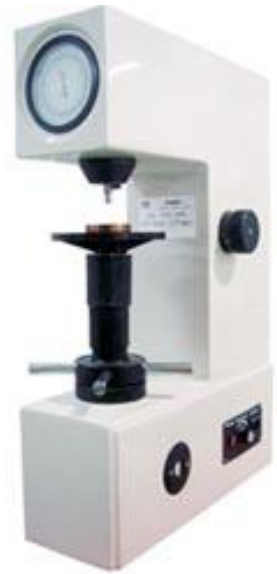

(b)

Gambar 3. Alat uji penelitian (a) Dapur listrik dan (b) Alat Uji Kekerasan

\subsection{Pembuatan Cetakan Roda Gigi}


Alat cetak roda gigi dibuat dari bahan stainless steel dengan desain yang telah dibuat seperti pada Gambar 4. Keterangan dari Gambar 4 tersebut adalah (1) Dies, (2) Plat dies, (3) Holder ejector, (4) Ejector, (5) Poros Ejector, (6) Holder punch dan (7) Punch.

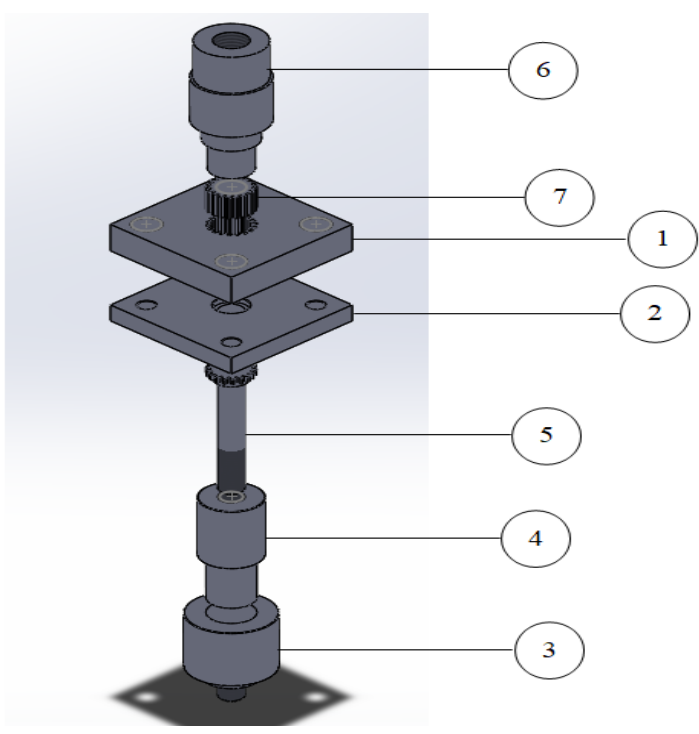

Gambar 4. Desain cetakan dan roda gigi

\section{Hasil dan pembahasan}

\subsection{Hasil}

Hasil penelitian berupa pengujian penekanan disajikan pada Tabel 1. Pada pengujian penekanan dilakukan pada waktu 60 detik dengan tinggi awal $13 \mathrm{~mm}$. Selain hal tersebut, diberikan dua variasi penekanan yaitu pada tekanan 9,4 MPa dan 11,1 MPa pada masing - masing variasi konsentrasi (\%) bahan serbuk.

Hasil pengujian sintering dan uji kekerasan ditunjukkan pada Tabel 2. Pengujian ini dilakukan pada 5 jenis roda gigi dengan variasi konsentrasi material penyusun yang berbeda. Gambar 5 menunjukkan persentase hasil pengamatan visual pada setiap jenis roda gigi dengan variasi konsentrasi material penyusun.

Tabel 1. Hasil Pengujian penekanan

\begin{tabular}{|c|c|c|c|c|c|c|}
\hline No & Gambar & Bahan Serbuk & $\begin{array}{l}\text { Waktu } \\
\text { (Detik) }\end{array}$ & $\begin{array}{c}\text { Tekanan } \\
(\mathrm{MPa})\end{array}$ & $\begin{array}{c}\text { Tinggi Awal } \\
(\mathrm{mm})\end{array}$ & $\begin{array}{l}\text { Tinggi Akhir } \\
\text { (mm) }\end{array}$ \\
\hline 1 & & & & 9.4 & 13 & 7.5 \\
\hline 2 & & & & 11.1 & 13 & 6.5 \\
\hline 3 & & & & 9.4 & 13 & 6.4 \\
\hline 4 & & & & 11.1 & 13 & 5.1 \\
\hline
\end{tabular}




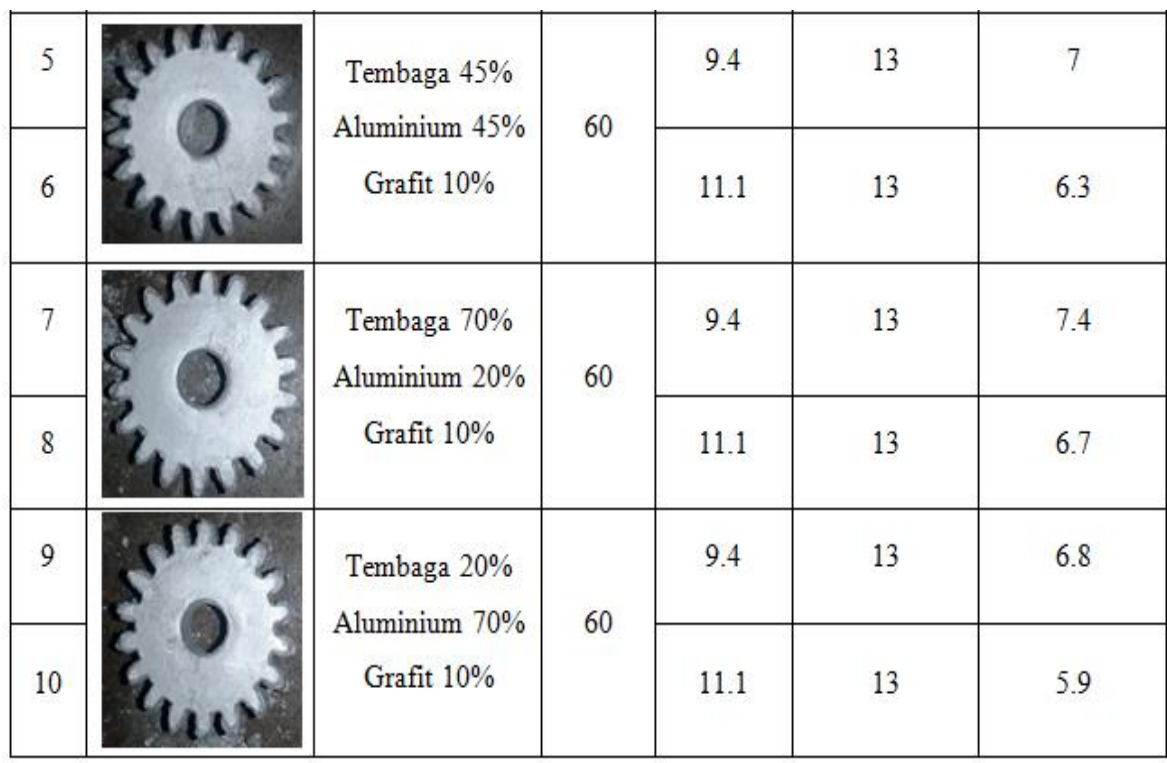

Tabel 2. Pengujian sintering dan uji kekerasan.

\begin{tabular}{|c|c|c|c|c|c|}
\hline No & Gambar & Material & $\begin{array}{c}\text { Uji } \\
\text { Kekerasan }\end{array}$ & $\begin{array}{c}\text { Pengamatan } \\
\text { Visual }\end{array}$ & Keterangan \\
\hline 1 & & Tembaga $100 \%$ & $\begin{array}{c}\text { Tidak } \\
\text { terdeteksi }\end{array}$ & Baik $90 \%$ & $\begin{array}{l}\text { Menyusut, } \\
\text { permukaan } \\
\text { kurang halus }\end{array}$ \\
\hline 2 & & $\begin{array}{l}\text { Aluminium } \\
90 \% \\
\text { Grafit } 10 \%\end{array}$ & $\begin{array}{c}\text { Tidak } \\
\text { terdeteksi }\end{array}$ & $\begin{array}{c}\text { Kurang Baik, } \\
\text { bentuk roda } \\
\text { gigi } 70 \%\end{array}$ & $\begin{array}{c}\text { Rapuh, terdapat } \\
\text { beberapa gigi } \\
\text { yang hancur }\end{array}$ \\
\hline 3 & & $\begin{array}{c}\text { Tembaga } 45 \% \\
\text { Aluminium } \\
45 \% \\
\text { Grafit } 10 \%\end{array}$ & $\begin{array}{c}\text { Tidak } \\
\text { terdeteksi }\end{array}$ & Baik $85 \%$ & $\begin{array}{c}\text { Permukaan } \\
\text { halus, tetapi } \\
\text { belum mencapai } \\
\text { tingkat } \\
\text { kekerasan yang } \\
\text { diinginkan }\end{array}$ \\
\hline 4 & & $\begin{array}{c}\text { Tembaga } \\
70 \% \\
\text { Aluminium } \\
20 \% \\
\text { Grafit } 10 \%\end{array}$ & $\begin{array}{c}\text { Tidak } \\
\text { terdeteksi }\end{array}$ & Baik $85 \%$ & $\begin{array}{l}\text { Terdapat bercak } \\
\text { putih pada gigi, } \\
\text { belum mencapai } \\
\text { kekerasan yang } \\
\text { diinginkan }\end{array}$ \\
\hline 5 & 20 & $\begin{array}{c}\text { Tembaga } 20 \% \\
\text { Aluminium } \\
70 \% \\
\text { Grafit } 10 \%\end{array}$ & $\begin{array}{c}\text { Tidak } \\
\text { terdeteksi }\end{array}$ & Cukup $75 \%$ & $\begin{array}{c}\text { Permukaan } \\
\text { retak, } \\
\text { permukaan gigi } \\
\text { kurang halus }\end{array}$ \\
\hline
\end{tabular}




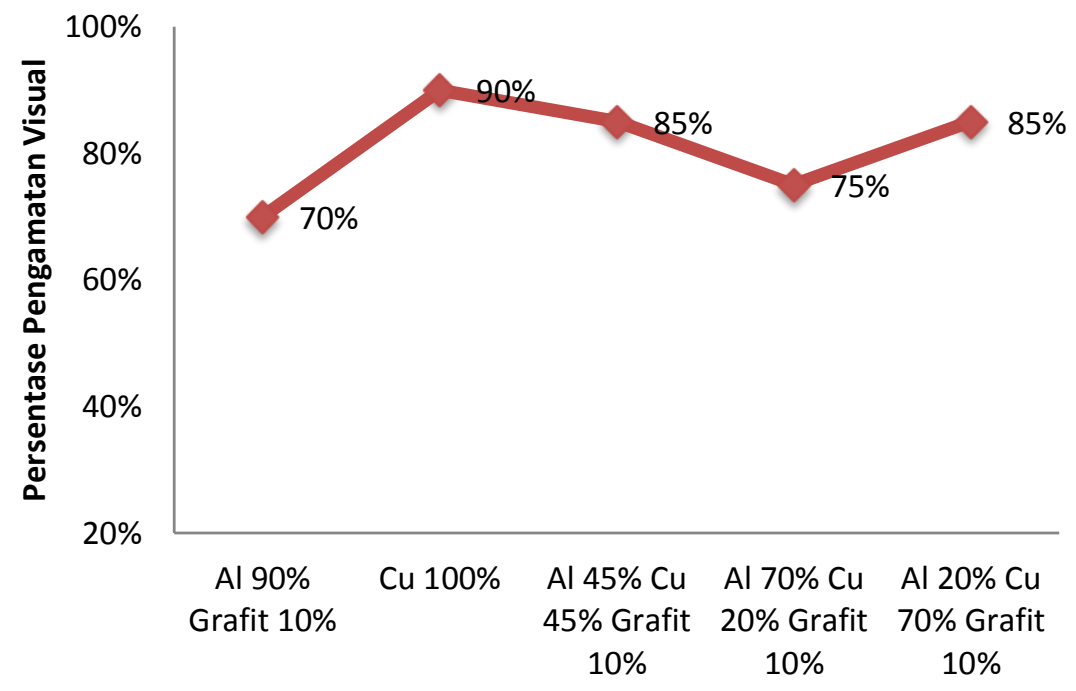

Gambar 5. Grafik Pengamatan Visual

\subsection{Pembahasan}

Penggunaan bahan tambah berupa serbuk grafit tidak memberikan pengaruh yang signifikan, dan dari hasil pengujian kekerasan dengan metode brinell di peroleh hasil yang tidak dapat terdeteksi oleh alat uji kekerasan, diduga karena bahan yang terlalu lunak. Berdasarkan tabel 2 diatas dapat di analisis sebagai berikut:

a. Analisis hasil sintering dengan bahan tembaga $100 \%$ dengan suhu sintering $868^{\circ} \mathrm{C}$

Setelah produk disintering kemudian diuji dengan mesin uji kekerasan, dan dilakukan pengamatan secara visual menunjukkan produk mengalami penyusutan pada bagian permukaan diduga penurunan suhu sinter ke suhu kamar terlalu ekstrem dan sifat produk yang belum mencapai kekerasan yang diinginkan diduga karena penekanan kurang pada saat pencetakan dan temperatur sintering kurang tinggi.

b. Analisis hasil sintering dengan bahan aluminium $90 \%$ dan grafit $10 \%$ dengan suhu sintering $528^{\circ} \mathrm{C}$

Setelah dilakukan pengujian dengan bahan aluminium $90 \%$ dan grafit $10 \%$ sebagai perekat menghasilkan produk yang kurang bagus dan rapuh, hal tersebut diduga bahan aluminium kurang cocok untuk proses metallurgy serbuk, sehingga bahan aluminium lebih memungkinkan untuk proses pengecoran logam.

c. Analisis hasil sintering dengan bahan tembaga $45 \%$, aluminium $45 \%$ dan grafit $10 \%$ dengan suhu sintering $528^{\circ} \mathrm{C}$

Hasil sintering produk dengan bahan paduan tembaga $45 \%$ dan aluminium $45 \%$ menggunakan grafit $10 \%$ sebagai perekat dengan suhu sintering $528^{\circ} \mathrm{C}$ menghasilkan permukaan roda gigi yang halus mungkin dikarenakan temperatur sinter untuk bahan aluminium yang sesuai, dan belum tercapainya kekerasan yang diinginkan mungkin disebabkan karena temperatur sinter untuk bahan tembaga kurang tinggi, sehingga partikel aluminium dan tembaga belum menyatu.

d. Analisis hasil sintering dengan bahan tembaga $70 \%$, aluminium $20 \%$ dan grafit $10 \%$ dengan suhu sintering $528^{\circ} \mathrm{C}$

Dengan bahan paduan tembaga $70 \%$ dan aluminium $20 \%$ menggunakan grafit $10 \%$ sebagai perekat dengan suhu sintering $528^{\circ} \mathrm{C}$ menghasilkan produk terdapat bercak putih pada gigi, hal ini mungkin dikarenakan penambahan bahan perekat yang terlalu banyak dan belum mencapai kekerasan yang diinginkan mungkin dikarenakan temperatur sinter untuk bahan tembaga kurang tinggi.

e. Analisis hasil sintering dengan bahan tembaga $20 \%$, aluminium $70 \%$ dan grafit $10 \%$ dengan suhu sintering $528^{\circ} \mathrm{C}$ 
Hasil sintering dengan bahan tembaga 20\%, aluminium 70\% menggunakan grafit $10 \%$ sebagai perekat dengan suhu sintering $528^{\circ} \mathrm{C}$ menghasilkan produk yang permukaannya kurang halus dan terdapat retakan, diduga karena penekanan pada saat pembuatan produk kurang, selain itu juga bahan aluminium yang kurang cocok untuk proses metallurgy serbuk.

\section{Kesimpulan}

Kesimpulan yang diperoleh dari pengujian ini adalah Alat cetak roda gigi dibuat berbentuk roda gigi dengan diameter $30 \mathrm{~mm}$ dan tinggi $15 \mathrm{~mm}$ dari bahan Besi Plat ST 60. Hasil pengujian kekerasan yang dilakukan terjadi pada roda gigi dari bahan serbuk tembaga $75 \%$ dan $25 \%$ aluminium. Produk yang dihasilkan setelah proses sintering belum mencapai tingkat kekerasan yang di inginkan diduga karena penentuan temperatur sintering kurang tepat, selain itu bahan aluminium mungkin kurang tepat untuk proses metallurgy serbuk.

\section{Daftar Pustaka}

[1] Abdul Syukur, dkk. Pembuatan Elektroda EDM Dari Bahan Serbuk Tembaga Dengan Proses Kompaksi. Jurnal Rekayasa Mesin Politeknik Negeri Semarang. 2018 Desember; 13 (3): p 91-96.

[2] Abdul Syukur, dkk. Rancang Bangun Alat Cetak Elektroda Electrical Discharge Machine Dengan Sistem Hidrolik. Politeknik Negeri Semarang. 2018.

[3] Abdul Syukur, dkk. Pembuatan Bushing Dari Bahan Serbuk Tembaga. Politeknik Negeri Semarang. 2016.

[4] Joseph and Capus, M.. Metal Powders, A global Survey of Production, Applications and Markets to 2010. El sevier Inc, New York. 2005.

[5] Murase, K., Honda,T. and Awakura, K. Measurement of pH in the Vicinity of a Cathode during the Chloride Electrowinning of Nickel. Journal of Mettallurgical and Material Transactions B, 29B. 1985 Desember; 1193.

[6] Nasser, A.M., Barakat.,Nasser, A. and Omran, M. Production of Beads Like Hollow Nickel Oxide Nanoparticles Using Colloid-gel Electrospining Methodology. Journal of Springer Science and Business Media, LLC. 2008. 